\title{
Ride Comfort Simulation of Electric Vehicle
}

\author{
Lv Lin ${ }^{1}$, Wang Jizhong ${ }^{1}$, Chen Shuai ${ }^{1}$, Yang Kebiao ${ }^{2}$ \\ ${ }^{1}$ College of Machinery and Automobile, Qingdao University of Technology, Qingdao, China \\ ${ }^{2}$ Foton Translation, Weifang, China
}

Email address:

279358678@qq.com (Lv Lin)

\section{To cite this article:}

Lv Lin, Wang Jizhong, Chen Shuai, Yang Kebiao. Ride Comfort Simulation of Electric Vehicle. International Journal of Intelligent Information Systems. Vol. 8, No. 1, 2019, pp. 18-25. doi: 10.11648/j.ijiis.20190801.14

Received: January 11, 2019; Accepted: March 4, 2019; Published: March 25, 2019

\begin{abstract}
Facing the new situation of global energy restructuring, occupying the highland of future industry competition and environmental protection, the major developed countries in the world will develop the electric vehicle industry to the national strategic level, and thus the electric vehicle has become the focus of competition among transnational automobile enterprises.In addition to ensuring the power performance of the vehicle, electric vehicles should also satisfy the safety and comfort of passengers and ensure the integrity of cargo transportation. Therefore, it is necessary to study the ride comfort and handling stability of electric vehicles.In this paper, the whole vehicle model is established by ADAMS/Car software, and the ride comfort simulation analysis is carried out. ADAMS/Car software is used to build the models of front suspension subsystem, power assembly subsystem, body subsystem, rear suspension subsystem, tire subsystem and steering subsystem, and then the models of each subsystem are assembled into the whole vehicle rigid body model. The elastomer model of the control arm is generated by setting MNF file, and the rigid-flexible coupling model of the control arm is established by replacing the rigid model of the control arm with the elastomer model. The ride comfort of the rigid-flexible coupling model is simulated and analyzed. The total weighted magnitude is 116.2646 . When the speed of the electric vehicle is $40 \mathrm{~km} / \mathrm{h}$, the passenger comfort is quite uncomfortable.
\end{abstract}

Keywords: Rigid-Flexible Coupling, Ride Comfort, Suspension, Dynamics, ADAMS/Car

\section{Introduction}

In the course of driving, vehicle vibration is caused by rough road surface and the role of rotating parts such as engine. Generally speaking, road surface roughness is the basic input of vibration, so ride comfort mainly refers to vehicle vibration caused by road surface roughness.

Vehicle ride comfort is to maintain the impact of vibration and impact environment on passenger comfort in the process of driving within a certain limit, so the ride comfort of the vehicle is mainly evaluated according to the subjective comfort of the passenger [1].

XIAO Wen-wen used ADAMS to build the models needed to study electric vehicles driven by hub motors. For example, vehicle model, motor model, road model and suspension model. With the increase of non-spring load quality, the ride comfort of electric vehicle driven by hub motor is studied. The results show that the vertical acceleration of the body and the dynamic load of the wheel are obviously affected by the change of the non-spring load mass, and both of them increase with the increase of the non-spring load mass. The increase of non-spring load quality leads to deterioration of vehicle driving performance [2].

YAO Mai taking a middle truck as the research object, he used Adams/Car to establish a multi-body dynamic model of vehicle ride comfort, and carried out ride comfort simulation analysis. Under the random excitation of grade A road surface and unbalanced excitation of tire, the influence of different driving speeds on vehicle ride comfort is analyzed, and the sensitivity of vehicle ride comfort parameters is analyzed. The influence of main factors such as bushing stiffness, shock absorber damping and leaf spring stiffness on vehicle ride comfort is studied [3]. 


\section{Establishment}

\subsection{Virtual Prototyping Technology}

Virtual prototyping technology refers to the process of product design and development, through the combination of various subsystems and simulation analysis technology, the whole rigid body or rigid-flexible model is established on the simulation analysis software, and the simulation analysis is carried out in various predicted realistic scenarios of the product, and then the possible performance parameters of the product are understood, so as to design the structure and function, etc. Summarizing and upgrading is a high and new technology at the forefront of development. The research of multi-body system dynamics is the origin of virtual prototyping technology. Although its core is the research of control theory, kinematics and dynamics, the advanced 3D graphics technology and design optimization technology based on 3D graphics make the virtual prototyping technology develop further. In addition, the popularization and application of $3 \mathrm{C}$ technology has also promoted the mature development of virtual prototyping technology [4]. First of all, designers can use the geometric modeling of drawing software to save working time and eliminate unnecessary drawing work so as to concentrate on solving design problems. In addition, researchers can further explore whether the model design is reasonable and correct. Secondly, three-dimensional modeling technology can make all aspects of the whole model system more clear and simple. Thirdly, 3C can quickly modify the design scheme of the design model through the powerful technology of three-dimensional modification and editing. Only in this way can we save unnecessary design workload and focus on product development.

Because virtual prototyping technology has abundant uses and takes account of customer's interface experience, it has stability performance. So it has been widely promoted in the market [5].

Virtual manufacturing technology was initially applied in the field of transportation, such as aircraft and automobiles. Among them, aircraft design and manufacture are the most dependent, because the cost of aircraft design and manufacture is too high, and its internal parts are too complex and expensive to bear the simulation experiments of multiple prototypes. In addition, many of the actual operating conditions of the aircraft can not be simulated in real environment, because the harm caused by it is very great, and it is not permitted by law and regulations. Under these restrictions, to meet all aspects of aircraft reliability and safety requirements, it is necessary to rely on this technology.

At present, virtual prototyping technology is gradually extended to aerospace, military science and technology, factory machinery and other fields besides the original aircraft and ship manufacturing industry. Its design products range from aerospace spacecraft to watch parts. It saves time and energy for researchers and developers in all fields of machinery manufacturing industry, and eliminates permission for consumers. With unnecessary costs, the development of contemporary society has gradually been inseparable from this technology [6].

In the field of production and processing, virtual prototyping technology plays an important role in the following aspects:

(1) Shape design of products. At the beginning of the year, the automobile appearance model was usually simulated by cheap foam. It had to be revised repeatedly to form, consume time and energy, and the result was not reliable and convincing. Through the design of computer virtual shape, arbitrary modifications can be made in the middle of the process, without worrying about the cost and time.

(2) Assembly simulation of products. In the process of product design, it is always a headache for researchers how to complete the correct mechanical system with assembly. If the assembly errors cannot be found in the design process, the final assembly errors will lead to product scrapping, which will bring great economic losses. Therefore, virtual assembly technology is very necessary and reliable in this respect. It can help users to verify whether the product assembly is reasonable, ensure the quality and quantity of the completion time, ensure the quality and avoid losses in the design stage.

(3) Kinematics and dynamics simulation of the product. Virtual prototyping technology can help designers to simulate their functions and performances conveniently on the computer, and avoid the failure of actual working conditions after the design is completed.

\subsection{Vehicle Dynamics Model}

In order to reflect the vehicle's handling stability accurately and practically, the detailed features of the vehicle can be simplified and ignored to ensure that the necessary parameters are accurate [7]. The process of building model in Adams/car is template-subsystem-assembly [8]. The modeling steps in this paper are as follows:

1) In order to avoid the complexity of modeling, this paper only modeled the flexible body of elastic components, and the rest of the components are regarded as rigid body models. The front suspension of this electric vehicle is McPherson type, so this paper establishes the corresponding McPherson suspension, which consists of lower control arm, steering knuckle, shock absorber and coil spring.

Before establishing the model of the front suspension subsystem, it is necessary to determine the parameters of the hard points of the front suspension and modify the coordinates of the hard points of the formwork to obtain the rigid McPherson suspension model. As shown in Figure 1 (a).

2) The rear suspension of electric vehicle adopts torsion beam suspension. The torsion beam suspension only relies on a single torsion beam to adjust the jump of the relative wheel to maintain stable balance, thereby reducing the body swing and ensuring the reliability of the vehicle. Because the torsional beam structure has considerable torsional stiffness, which is equivalent to 
the lateral stabilizer bar, it can improve the roll stiffness and reduce the possibility of vehicle rollover.

Because the torsion beam rear suspension structure is simple to build, low cost to make, easy to maintain, occupies a small space, can reduce the chassis height, can increase a certain amount of occupant space, so it is often used in smaller cars. The rear suspension adopts torsion beam suspension and the torsion beam suspension formwork in Adams/car. As shown in Figure 1 (b).

3) The steering system of electric vehicle is rack-and-pinion steering system, which consists of steering transmission shaft, steering wheel, steering knuckle arm, steering gear and steering tie rod. Its working principle is that when the driver rotates the steering wheel, the pinion follows the rotation, the combination of pinion and rack will drive the rack to move in a straight line from left to right, and drive the steering wheel to swing, so as to achieve the purpose of steering.

Compared with other steering gear, rack-and-pinion steering gear has the advantages of simple structure, small space occupied, good transmission efficiency, no steering rocker, low manufacturing cost and so on. Therefore, it is now widely used in cars. As shown in Figure 1 (c).

4) Power assembly is an important part of forming power in automobiles and transmitting power to the driving road surface. The main power assemblies on automobiles are engine, drive shaft, clutch, gearbox and differential. First, the engine converts thermal energy into mechanical energy, and then the power is transmitted to the wheel through clutch, transmission, transmission shaft, axle, etc. By modifying the hard point parameters, the power assembly subsystem model is established. As shown in Figure 1 (d).

5) Automotive tire system is an integral part of the automobile, and its mechanical performance and structural parameters have a very important impact on the driving performance of the automobile. The road forces and moments exerted on the tire system affect the driving performance of the vehicle. Therefore, the tire model has a vital impact on the simulation research and results of vehicle model dynamics. The tire precision must be designed by referring to the vehicle model, and the tire has a rather complex structure and multiple forces, so the appropriate tire model should be selected. Pacejka89 tire model adopted in this paper. As shown in Figure 1 (e).

6) Ignoring the appearance of the body, the body model is simplified to a mass point, and the inherent body model of Adams/Car is used. As shown in Figure 1. (f).

7) After assembling the subsystem with the vehicle test bench, the rigid-flexible coupling model of the vehicle is obtained, as shown in Figure $1(\mathrm{~g})$

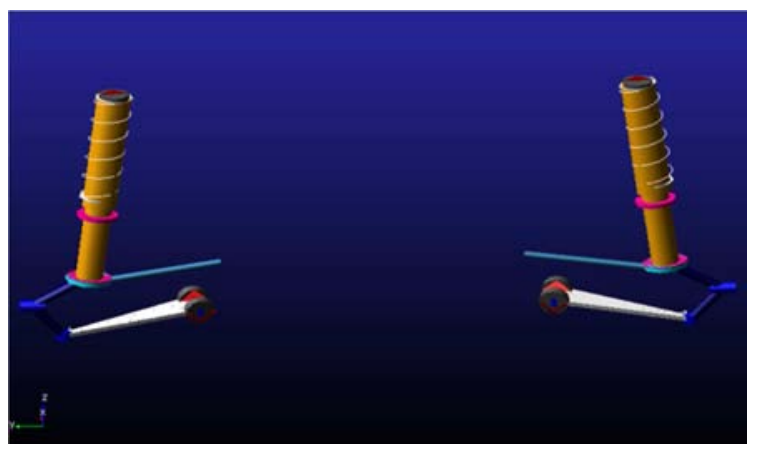

(a)

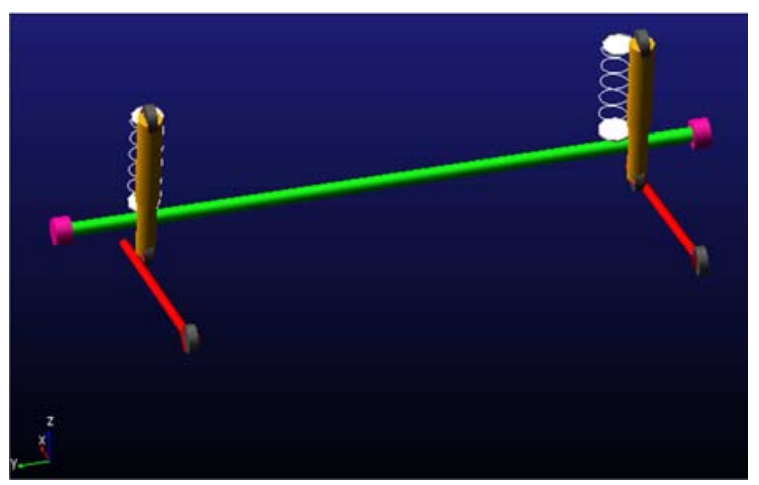

(b)

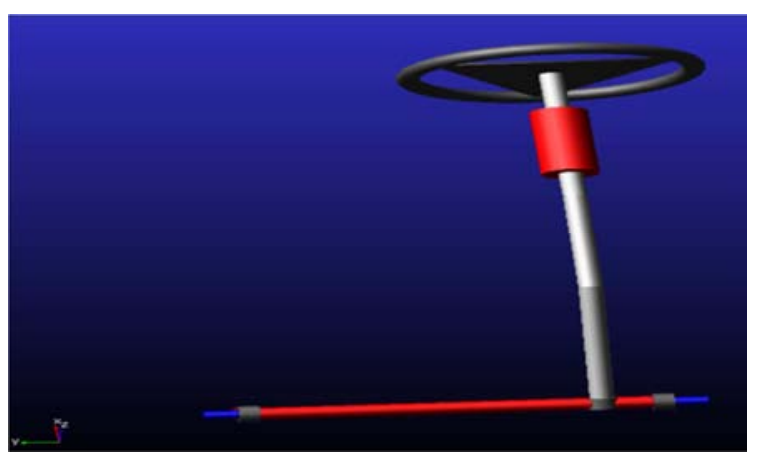

(c)

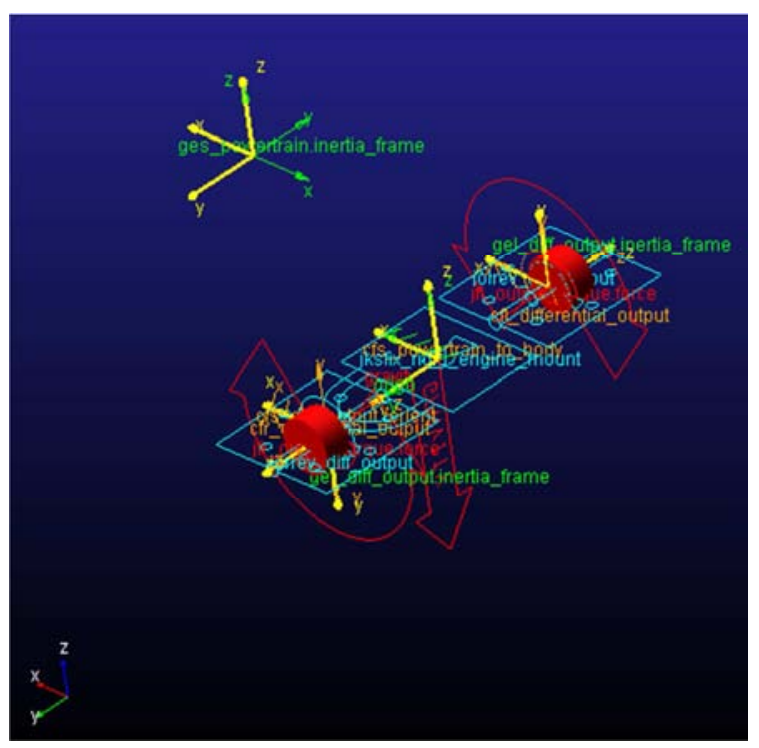

(d) 


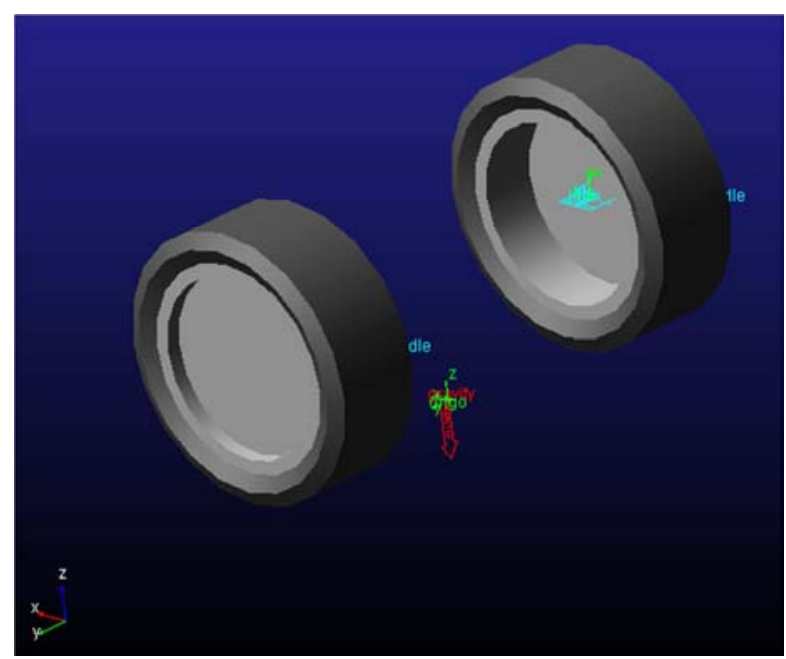

(e)

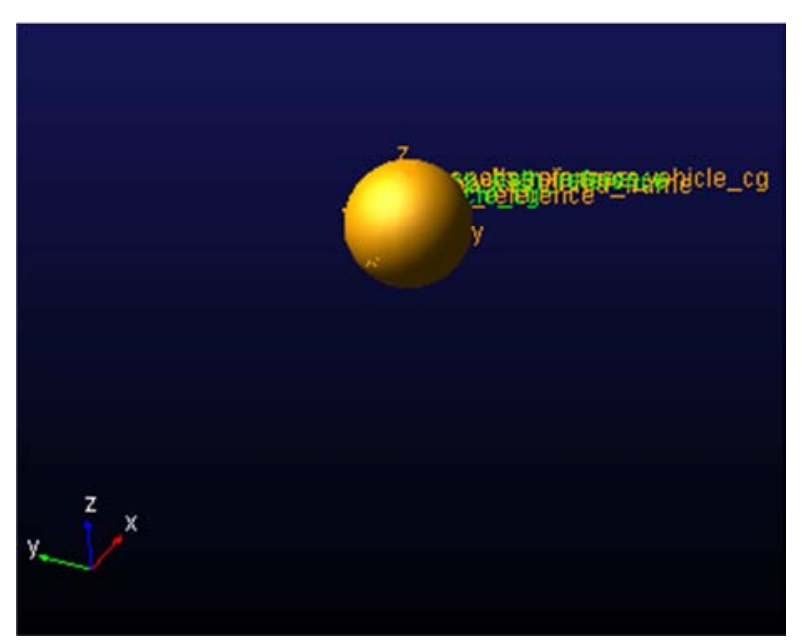

(f)

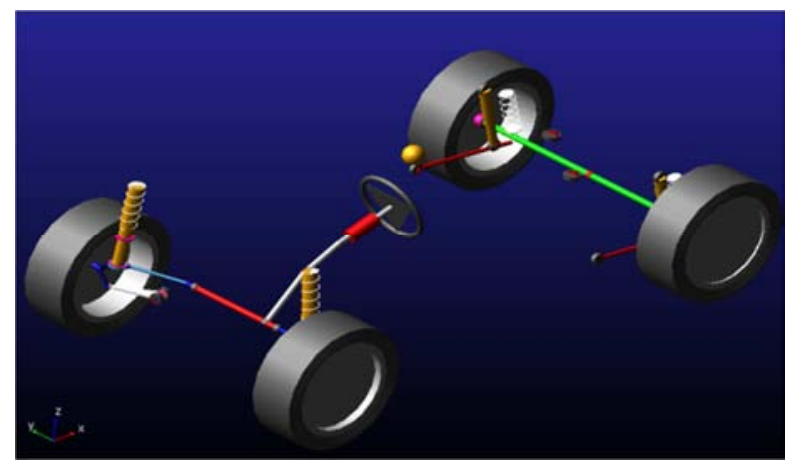

(g)

Figure 1. Subsystems and Vehicle Assembly. (a)McPherson front suspension. (b)Torsion beam rear suspension. (c)steering system. (d)Powertrain. (e)Tire system. (f)Body model. (g)Vehicle model.

\section{Evaluation Method of Vehicle Ride Comfort}

Acceleration-time $a(t)$ was calculated by spectrum analysis and calculated according to the formula:

$$
a=\left[\int_{0.5}^{80} W^{2}(f) G_{a}(f) d f\right]^{\frac{1}{2}}
$$

When it is necessary to consider the axial vibration of the chair in three directions simultan -eously, the RMS values of the three axes are calculated according to the following formulas:

$$
a_{v}=\left[\left(1.4 a_{x w}\right)^{2}+\left(1.4 a_{y w}\right)^{2}+a_{z w}{ }^{2}\right]^{\frac{1}{2}}
$$

In this paper, the basic method is used to evaluate the ride comfort of Reading D50 electric vehicle. Because the method is applicable to all normal driving conditions, the second method is used to evaluate the ride comfort of the vehicle, which integrates the processing and analysis functions of the software [9].

\section{Ride Comfort Simulation}

\subsection{Establishment of Random Pavement}

Before the ride comfort simulation analysis of vehicle rigid-flexible coupling model, it is necessary to establish a suitable random road surface model, which has a vital impact on the analysis results and is a prerequisite for ride comfort simulation. Firstly, Random Pavement Generator is used to generate Class A pavement. As shown in Figure 2. Refer to Table for the parameter definition of random pavement.

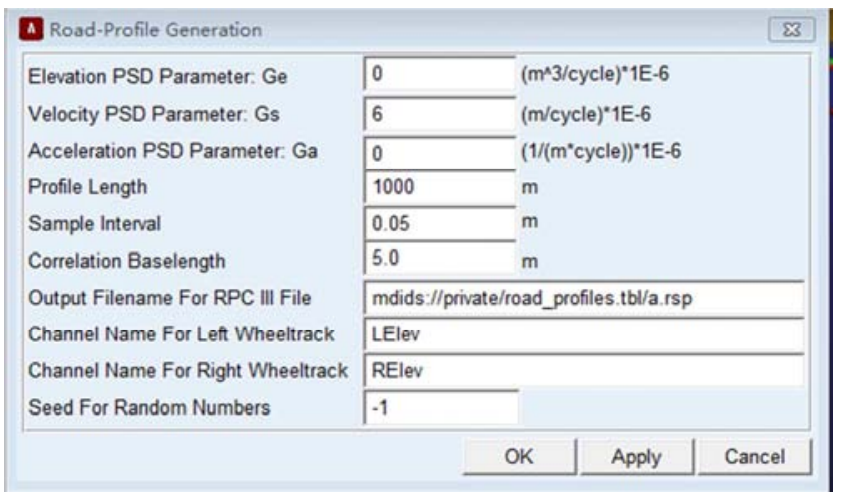

Figure 2. Power Spectrum.

Table 1. Random Pavement Power Spectrum.

\begin{tabular}{llll}
\hline Pavement type & $\boldsymbol{G}_{\boldsymbol{e}}$ & $\boldsymbol{G}_{\boldsymbol{s}}$ & $\boldsymbol{G}_{\boldsymbol{a}}$ \\
\hline Asphalt pavement & 0 & 12 & 0.17 \\
Smooth asphalt pavement & 0 & 6 & 0 \\
Rough asphalt pavement & 0.003 & 20 & 0.20 \\
Cement pavement & 0.1 & 20 & 0.25 \\
Smooth cement pavement & 0 & 1 & 0 \\
Rough cement pavement & 0.1 & 35 & 0.3 \\
\hline
\end{tabular}

\subsection{Ride Comfort Simulation}

Set the speed of $40 \mathrm{~km} / \mathrm{h}$ for simulation analysis, as shown in Figure 3, the simulation results are shown in Figure 4. 


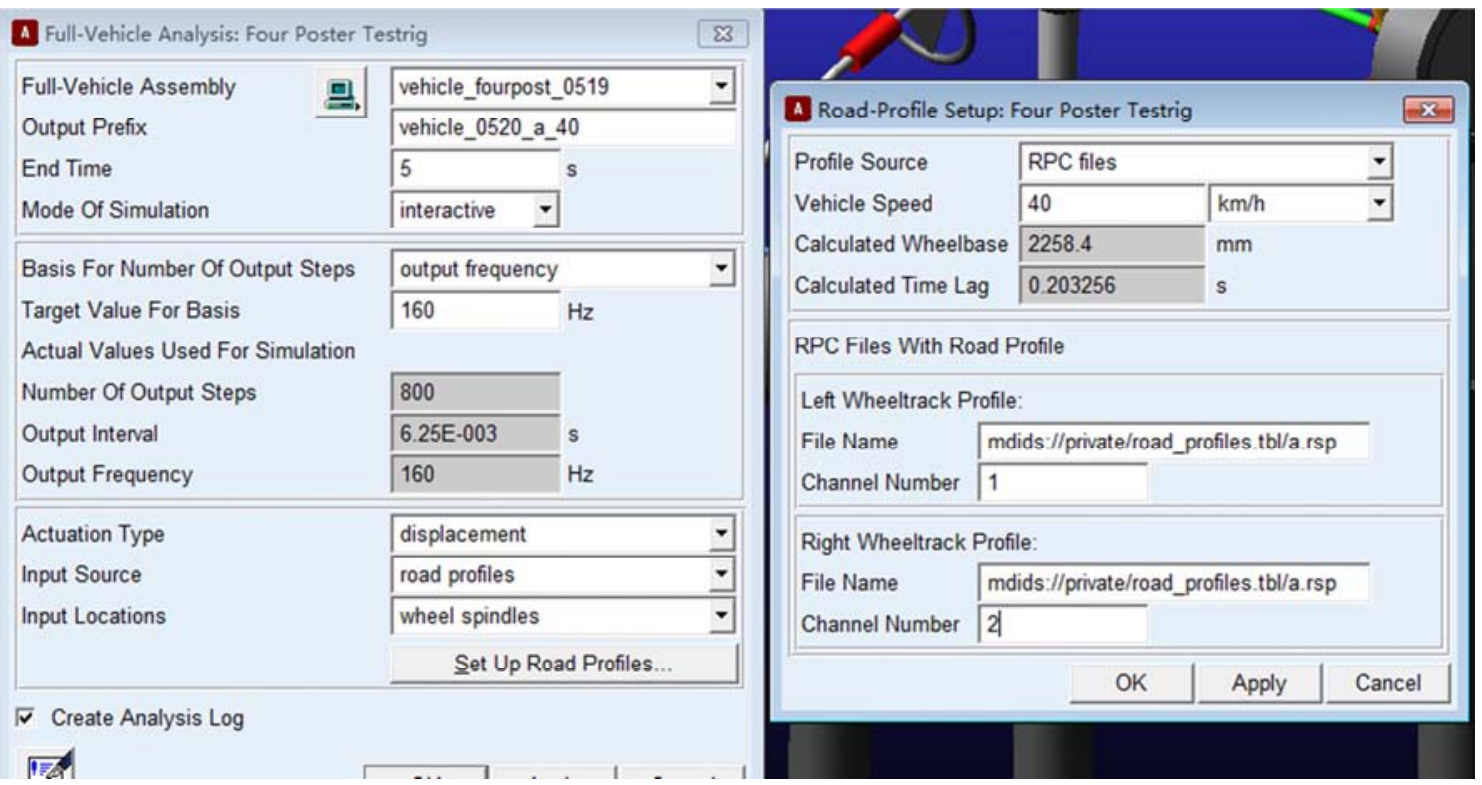

Figure 3. Full-Vehicle Analysis: Four Power Testing.

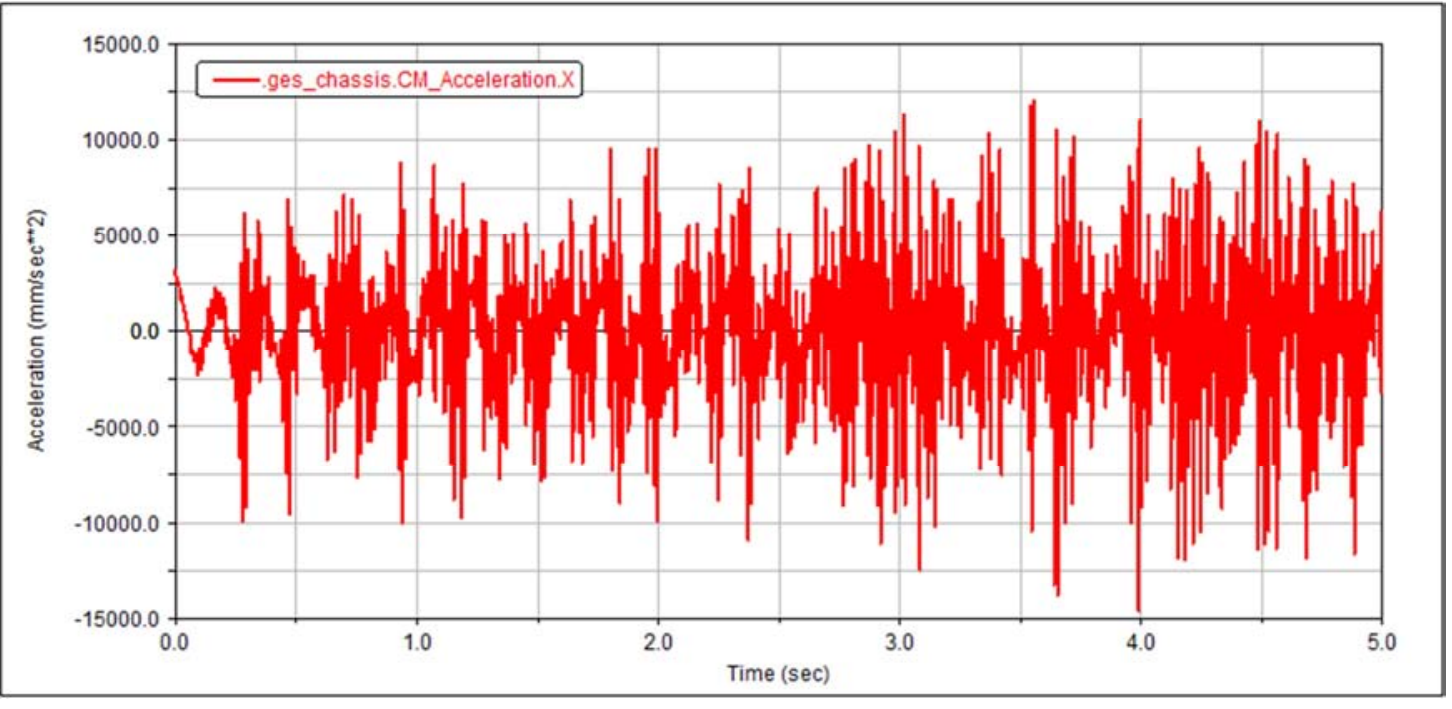

(a)

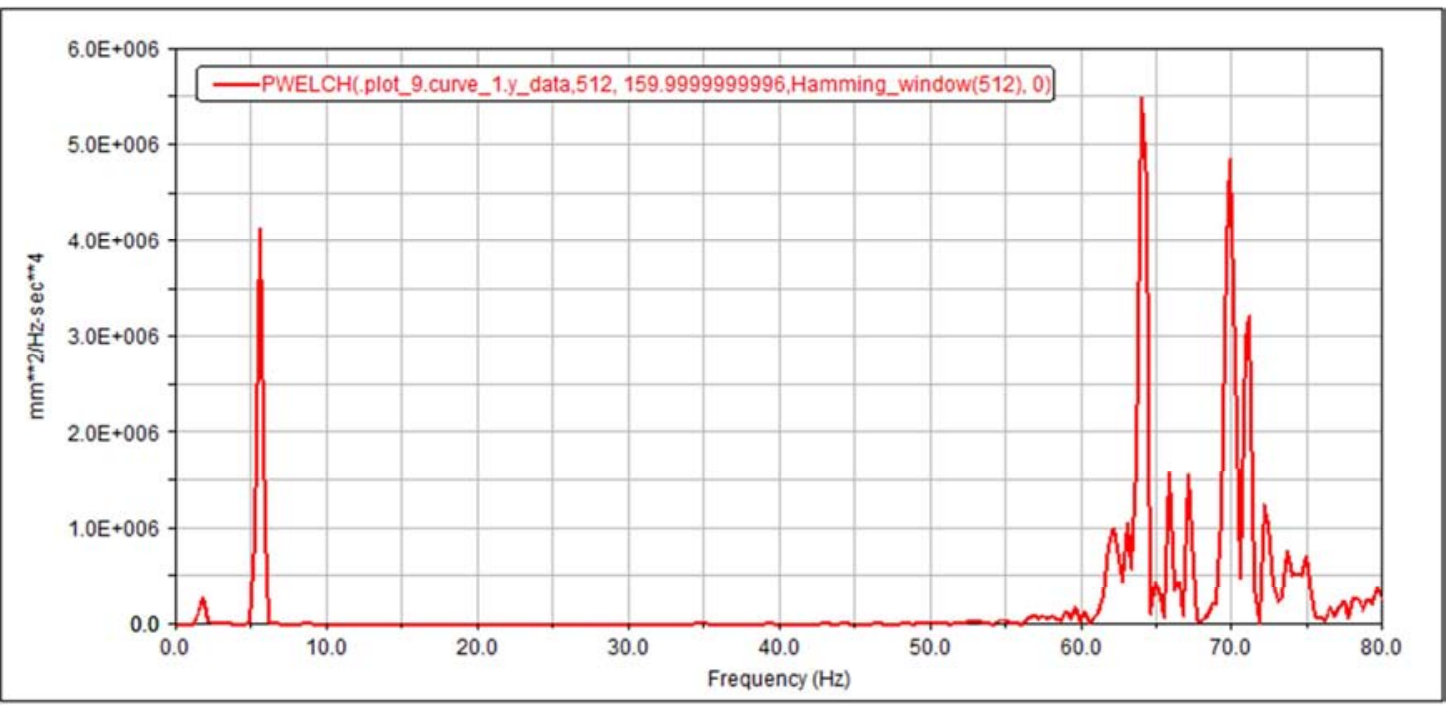

(b) 


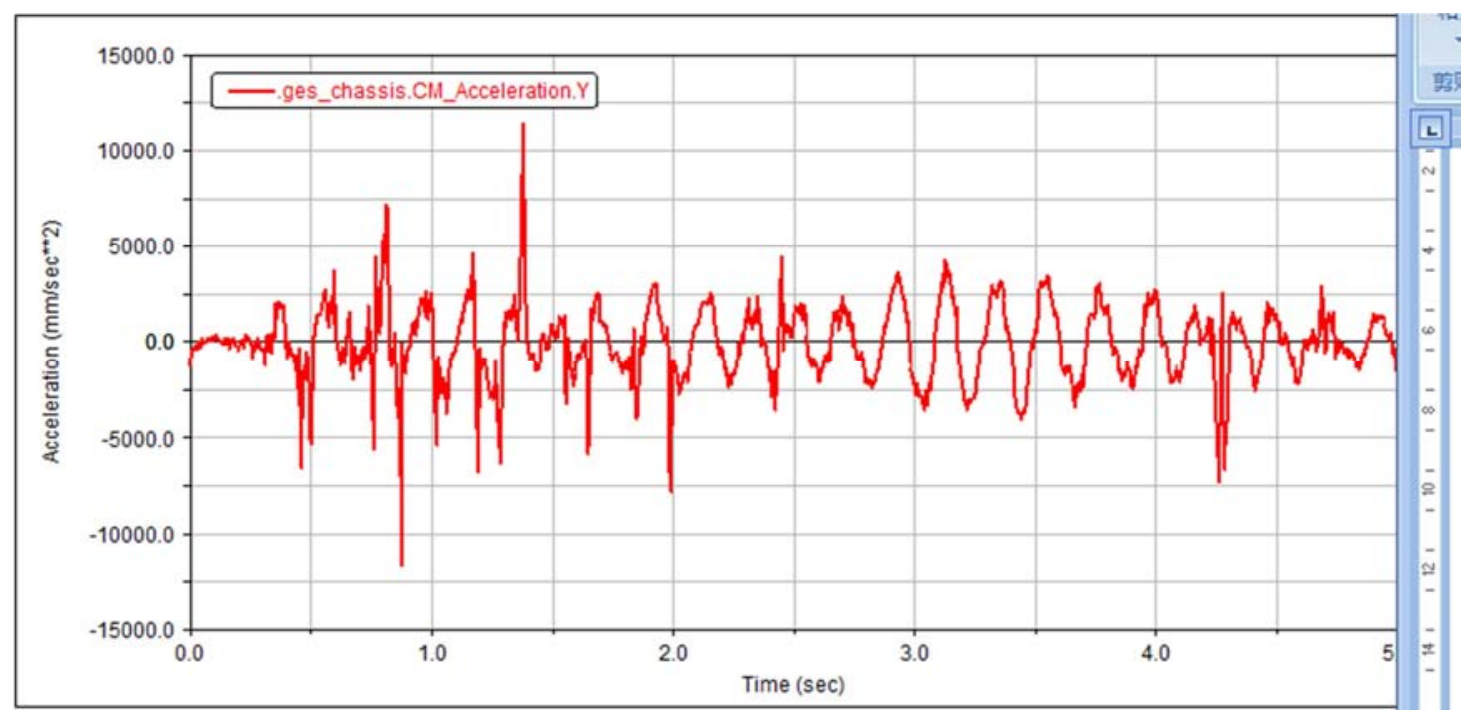

(c)

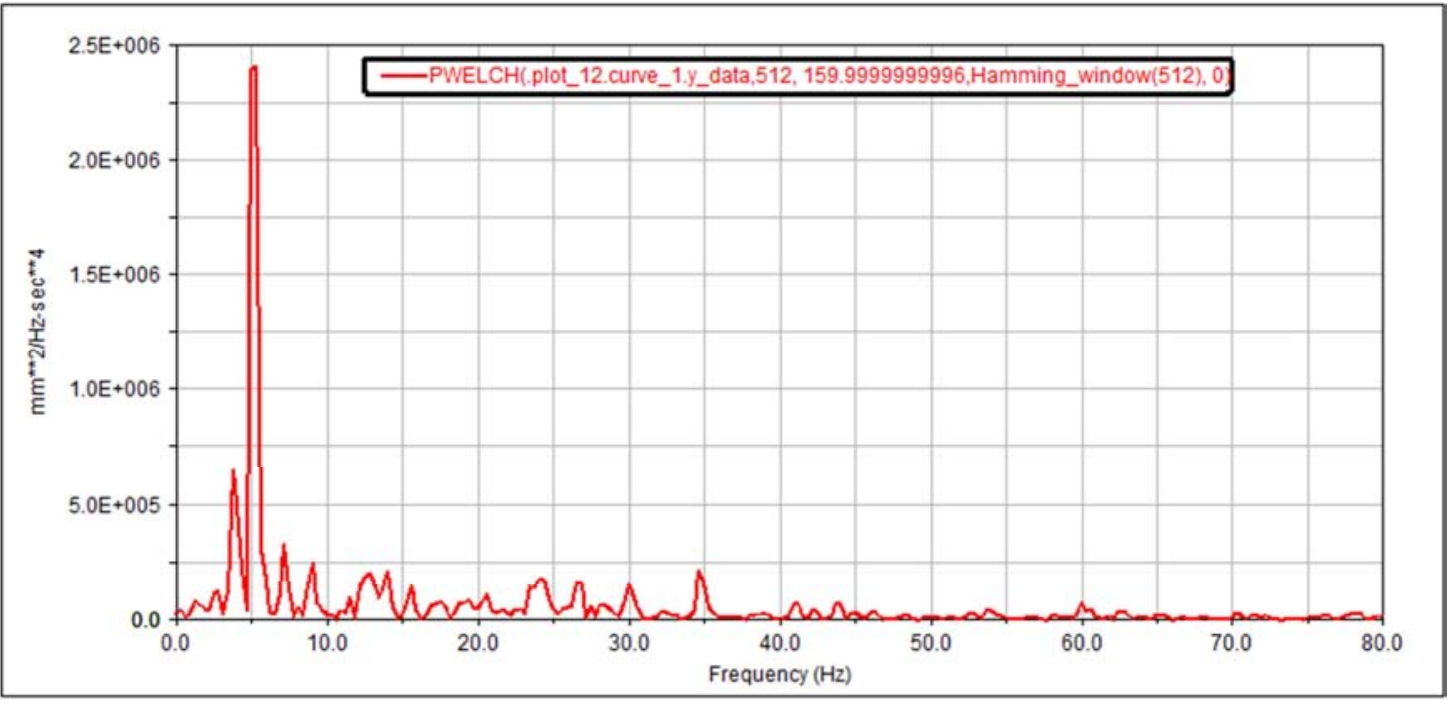

(d)

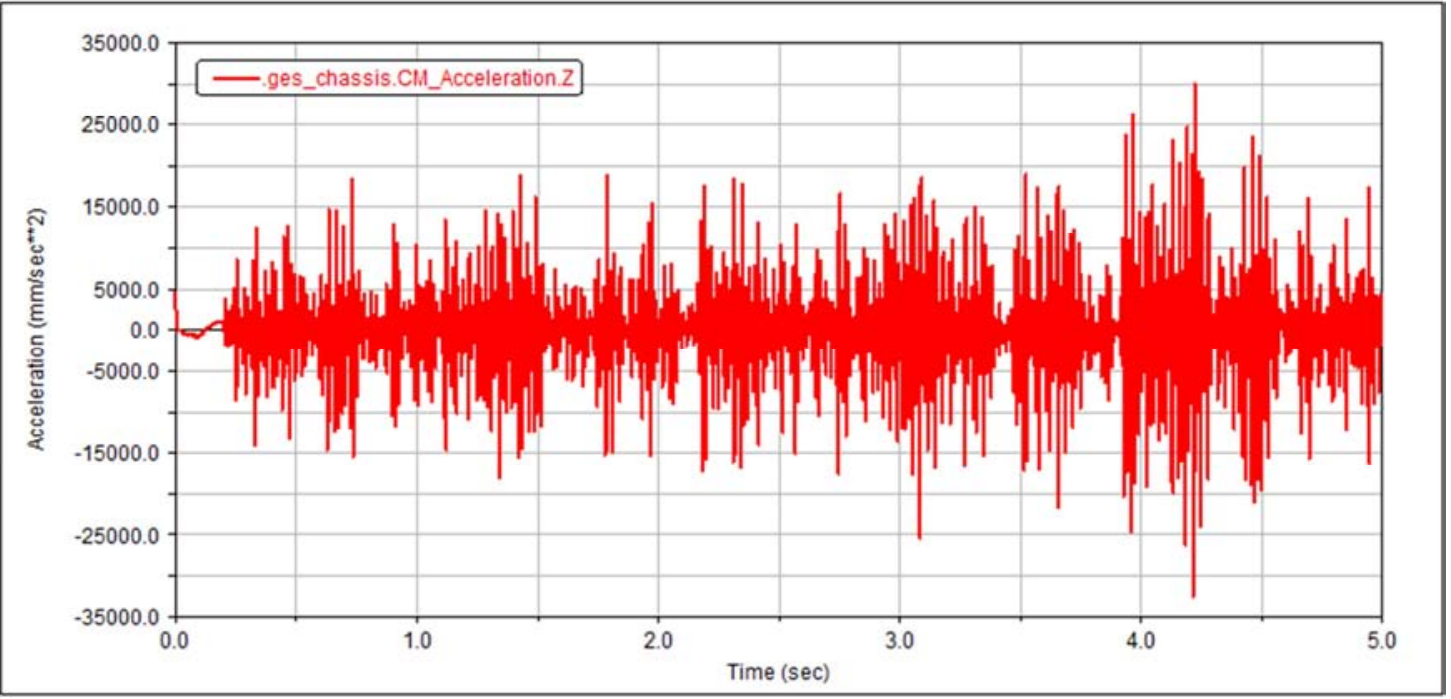

(e) 


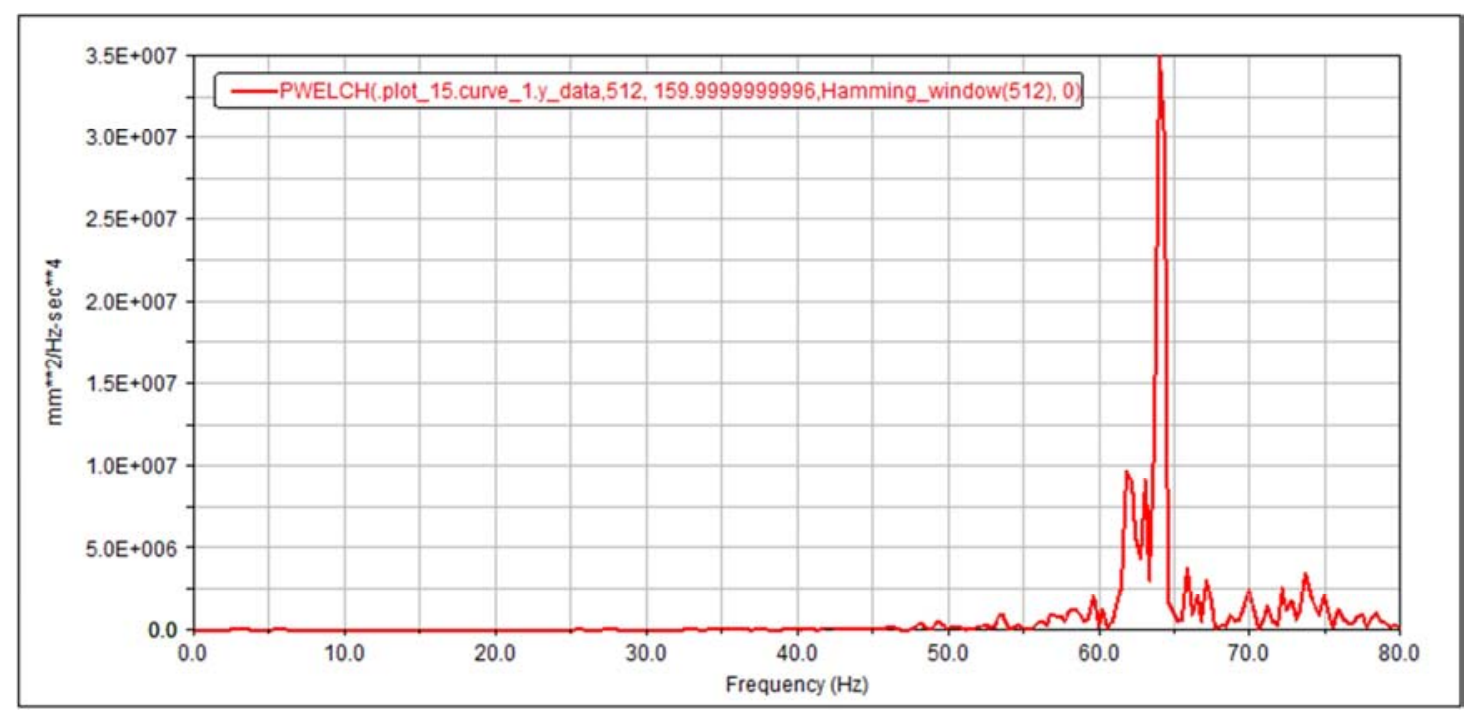

(f)

Figure 4. Postprocessing results of smoothness. (a) X-direction acceleration time histogram. (c) Y-direction acceleration time histogram. (b) X-direction acceleration power spectrum. (d) Y-direction acceleration power spectrum. (e) Z-direction acceleration time histogram. (f) Z-direction acceleration power spectrum.

According to the above pictures, the weighted root mean square acceleration at the driver's seat is measured when the vehicle speed is $40 \mathrm{~km} / \mathrm{h}$ under Class A road surface. The value of RMS along the $X$ direction is 0.1763 ; the value of RMS along the $\mathrm{Y}$ direction is 0.2248 ; The value of RMS along the $\mathrm{Z}$ direction is 0.6505 . Calculating the Total Weighted Vibration Level is 116.2646.

Calculated results: $a_{v}=0.6505$

Then according to the formula:

$$
L_{\mathrm{aw}}=20 \lg \left(a_{v} / a_{0}\right)
$$

The RMS value of reference acceleration is $10^{-6} \mathrm{~m} * \mathrm{~s}^{-2}$ taken in the formula. The total weighted magnitude is 116.2646 . When the speed of the electric vehicle is $40 \mathrm{~km} / \mathrm{h}$, the passenger comfort is quite uncomfortable.

\subsection{Improvement Plan}

Based on the previous analysis of this chapter, it can be seen that under the premise of keeping the original design as much as possible, the ride comfort of the vehicle can be optimized from the spring stiffness of the suspension and the damper of the shock absorber. When changing the stiffness of suspension spring, attention should be paid to the matching of front and rear suspension bias. The natural frequency of the vibration system consisting of the front and rear suspension and its spring mass is one of the main parameters affecting vehicle ride comfort. The mass distribution coefficient of modern automobiles is approximately equal to 1 , so there is no relationship between the vibration of the front and rear axles of automobiles [10].

The optimization scheme proposed in this paper is to replace the coil spring on the original vehicle suspension with the air spring. The selection of the air spring should match the damp of the suspension properly and test its effect on improving the ride comfort of the vehicle. The application of air suspension in high-end cars is also a general trend, which depends on the excellent characteristics of air suspension itself, and the effect is considerable. Moreover, with the improvement of air spring technology and the reduction of cost, the popularization of air suspension will become the future trend.

\section{Conclusion}

In the analysis of vehicle ride comfort, take random road ride comfort simulation, defining the position for the driver's seat, the acceleration curve measured $\mathrm{X}, \mathrm{Y}, \mathrm{Z}$ direction, the total weighted acceleration vibration level obtained by calculation, verification of automobile ride comfort.

Based on the rigid-flexible coupling model of the whole vehicle, ride comfort simulation analysis is carried out on A-grade road surface. When the vehicle speed is $40 \mathrm{~km} / \mathrm{h}$, ride comfort of the electric vehicle is rather uncomfortable and ride comfort is uncomfortable.

Replacing coil spring with air spring can effectively improve ride comfort and passenger comfort.

\section{Acknowledgements}

This paper was completed under the kindly care and careful guidance of my instructor. From software learning to simulation analysis, Mr. Wang has always patiently guided me step by step. With the help of the teacher, I did not lose my direction in the design and successfully completed it. Professor Wang's rigorous attitude towards scientific research and his spirit of pursuing excellence are all what I need to learn. Thank you for your help.

Thank my roommates and classmates who fought with me, especially my classmates for their help, and my elders for their help and design parameters. I sincerely wish you all the best in your future work. 
Thank you all for taking the time to guide my paper.

\section{References}

[1] M. P. Bendse, O. Sigmund. Topology Optimization: Theory, Methods, and Applications, Springer, Berlin, 2003.

[2] XIAO Wen-wen, ZHANG Huan-huan, XUAN Fei-hu. Research on ride comfort of electric vehicle driven by hub motor based on ADAMS/Car software [J]. Manufacturing Automation, 2018 (7).

[3] YAO Mai. Modeling and Simulation of ride comfort of a middle card based on Adams [J]. Journal of Hefei University (Comprehensive Edition), 2017 (2).

[4] Murali M. R. A methodology of using topology optimization in finite element stress analysis to reduce weight of a structure [J]. SAE Paper, 2001-01-275

[5] Laxman S, Mohan R. Structural optimization: Achieving a robust and light-Weight design of automotive components [J]. SAE Paper, 2007-01-0794
[6] Kim BS, Koschel W. Shape optimization of a front suspension fork according to the axiom of constant stress [J]. SAE Paper, 1999-01-0032

[7] W. Sunada, S. Dubouwky, The application of finite element methods to the dynamic analysis of flexible spatial and co-planar linage systems, Journal of Mechanical Design, 1971, (103): 643-651.

[8] Laxman S, Mohan R. Structural optimization: Achieving a robust and light-Weight design of automotive components [J]. SAE Paper, 2007-01-0794.

[9] Xue Guan Song, Ji Hoon Jung, Hwan Jung Son, Joon Hong Park, Kwon Hee Lee, Young Chul Park. Metamodel-based optimization of a control arm considering strength and durability performance $[\mathrm{J}]$. Computers and Mathematics with Applications 2010(10): 976-980.

[10] Shen Tao, Li Fei, Su Tianchen, et al. Dynamic Performance Simulation Analysis and Research of Air Suspension Vehicle [J]. Automotive Practical Technology, 2017 (21): 55-58+61. 